\title{
Study of the industrial contaminations containing hydrocarbon components and their effect on correlation of protective properties of textiles for clothes
}

\author{
Irina Cherunova*, Elena Yakovleva, and Ekaterina Stefanova \\ Don State Technical University, Institute of Service and Business, 346500 Shakhty, Russia
}

\begin{abstract}
The article represents trends and results of world investigations for safety of textile materials for humans and environment. The algorithm for identification of potential influence vector of chemical emissions from textile and the environmentally aimed methods based on the alternative chemical substances for textile wet processing were presented. Using the procedure for oleophobic effect determination, the oil resistance levels of a number of modern fabrics for clothes were established. The experimental research results of the oil products concentration in the textile materials after chemical treatment based on the method of the capillary gas chromatography were presented. It was found out that hydrocarbons from $\mathrm{C} 14 \mathrm{H} 30$ Tetradecane to $\mathrm{C} 36 \mathrm{H} 74$ Hexatriacontane are the main components with high level of contaminants concentration. The average values of hydrocarbon concentration on the cleaned up samples for the main areas of the clothe surface were determined. Accumulation of residual contaminations, based on saturated hydrocarbons $(\mathrm{C} 17 \mathrm{H} 36$ C25H52 block) and related special-purpose clothes areas, was identified. Recommendations for target-oriented correlation of the clothes protective properties were proposed. UWO (unified work order). The research was made in Don State Technical University within the framework of State Assignment of the Ministry of education and science of Russia under the project 11.9194.2017/BCh.
\end{abstract}

\section{Introduction}

Human safety system at production site is ensured by the special actions and means. The clothes [1] belong to the human personal protective equipment. Progress of production technologies in combination with environmental conditions generates new requirements to the protective clothes that shall provide countermeasures against physical, chemical, biological and psychological risks. The global community expansion of interest to technologies for development and processing of the power resources results in demand for development of special-purpose clothes material properties [2]. The feature of the environmental factors is increased concentration of contaminations having aggressive effect

*Corresponding author: i_sch@mail.ru 
on the special-purpose clothes surface [3]. To a great extent, the clothes surface features for the properties of the materials. Such materials are often made using special fibres and coatings [4]. The current protective coatings of the textile materials are determined by composition of polymers. The maximum effect of such materials exist upon no other chemical substances available in their structure and surface. Evaluation of the expected protective coating material efficiency depends on the material structure, composition of chemical components and effectiveness of their elimination using chemical technologies for the clothes cleaning from the current production contaminations [5]. Therefore, the task for contaminations investigation on the oil production facilities and estimation of clothes materials protection stability during application of chemical treatment technologies are relevant to science and current labour safety production technologies.

\section{Relevance and scientific merit of the problem}

Figures The clothes contaminations exist in 3 phases: solid, liquid and gaseous (for contaminants - dry, liquid and oily). The dry contaminants consist of organic and mineral origin pigment substances. The oily type contaminations relate to different substances for machinery and equipment servicing. The issues of contaminations in the textile technologies are studied in a lot of the world research centres. The first direction evaluation of environmental contaminations from textile technologies immediately [6]. The content of substances in textile and environment during textile production are considered in this direction. At that, the textile materials are taken without any fibre external contamination [7]. The Swedish scientists [5] developed the algorithm for determination of potential influence vector for the chemical emissions from the textile.

It was found that the harmful chemical components in the textile materials for clothes could accumulate within the range of special chemical colourants. Table 1 displays the data on proportion of unfixed colorants during dying of various fibrous materials [8].

Table 1. Composition of dyes for textile margins.

\begin{tabular}{|c|c|c|}
\hline Fibre & Dye type & $\begin{array}{c}\text { Unfixed due } \\
\mathbf{\%}\end{array}$ \\
\hline \multirow{3}{*}{$\begin{array}{c}\text { Wool and } \\
\text { nylon }\end{array}$} & $\begin{array}{c}\text { Acid dyes/reactive dyes } \\
\text { for wool }\end{array}$ & $7-20$ \\
& $\begin{array}{c}\text { Premetallized dyes } \\
\text { After chromes }\end{array}$ & $2-7$ \\
& Azoic dyes & $2-2$ \\
\hline & Reactive dyes & $20-50$ \\
Cotton and & Direct dyes & $5-20$ \\
viscose & Pigment & 1 \\
& Vat dyes & $5-20$ \\
& Sulphur dyes & $30-40$ \\
\hline Polyester & Disperse & $8-20$ \\
Acrylic & Modified basic & $2-3$ \\
\hline
\end{tabular}

The scientists from India [9] made it possible to create the environmentally aimed methods based on the alternative chemical substances for textile wet processing.

However, the analysis of the world science achievements demonstrates that most of research trends allow determining, manifestation of textile chemical components with no regard to external contaminations on the production site. Eco-friendly alternative chemicals for textile wet processing is presented in table 2 . 
Table 2. Chemical components for eco-processing of textiles

\begin{tabular}{|c|c|c|}
\hline Purpose & Chemical & Alternative \\
\hline Sizing & Starch & Water-soluble polyvinyl alcohol \\
\hline Desizing & Hydrochloric acid & Amylases \\
\hline Scouring of cotton & Sodium hydroxide & Pectinases \\
\hline Bleaching & Hypochlorites & Hydrogen peroxide \\
\hline $\begin{array}{c}\text { Oxidation of vat and } \\
\text { sulphur }\end{array}$ & $\begin{array}{l}\text { Potassium dishromate } \\
\text { Direct dyes }\end{array}$ & $\begin{array}{l}\text { Hydrogen peroxide } \\
\text { Sodium perborate }\end{array}$ \\
\hline Thichener & Kerosene & $\begin{array}{c}\text { Water-based polyacrylate } \\
\text { copolymers }\end{array}$ \\
\hline Hydrotropic agent & Urea & Dicyamide (partially) \\
\hline Water repellent & C8 fluorocarbons & C6 fluorocarbons \\
\hline Crease recovery chemicals & Formaldehyde-based resin & Polycarboxylic acids \\
\hline $\begin{array}{c}\text { Wettind agents and } \\
\text { detergents }\end{array}$ & Alkyl phenol ethoxylates & Fatty alcohol phenol ethoxylates \\
\hline Neutralization agent & Acetic acid & Formic acid \\
\hline Peroxide killer & Sosium thiosulphate & Catalases \\
\hline Mercerization & Sodium hydroxide & Liquid ammonia \\
\hline Reducing agents & Sodium sulphide & $\begin{array}{l}\text { Glucoe, acetyl acetone, thiourea } \\
\text { dioxide }\end{array}$ \\
\hline Dyeing & Powder form of sulphur dyes & Prereduced dyes \\
\hline Flame retardant & Bromated diphenyl ethers & $\begin{array}{c}\text { Combination of inorganic salt and } \\
\text { phosphonates }\end{array}$ \\
\hline Shrink proofing & Chlorination & Plasma treament \\
\hline
\end{tabular}

With that, the production facilities for extraction and processing of power purpose hydrocarbon products are of particular interest, because they are accompanied with chemical substances not in the liquid and solid phase only, but in the gaseous state as well.

The stability level of the protective material characteristics is determined by the material composition and structure, the aggregates of the chemical substances deposited in the material layer and by efficiency of technologies for chemical elimination of such contaminations, which requires additional research works. 


\section{Identification of research objectives}

This work scope is to determine compliance of current methods for chemical cleaning of textile materials from aggressive components of the oil-containing contaminations for forecasting human personal protection technologies on the production site.

The following tasks will be solved:

- justification of types and structure of materials for protective clothes;

- identification of the clothes material contamination components based on the example of the refinery complex production conditions;

- experimental research of the oil products concentration in textile products after chemical cleaning;

- formulation of conclusions and main recommendations.

\section{Theoretical and experimental procedure}

Contamination collection rate of fabrics and strength of contaminations retention depends on the fabric fibrous composition and structure. The fabric is less contaminated the more the fabric surface is dense and even. The initial material processing technology methods and the components of external contaminations form the specific system "clothes-materialscoatings-contamination-saturation-local protection-total protection" [11].

The materials based on cotton and cotton-lavsan mixture are used for oil refinery workers' clothes.

Crude oil, its refinement products and oils are able to penetrate the fabric fibres, which is due to their high volatility and low surface tension [12]. At that, they can contaminate special-purpose clothes, penetrate into underclothing space and contact the human skin, thus, changing the total level of the protective properties [13].

To study the protective capability of materials, the procedure for fabric oleophobic effect (oil resistance) determination was used [14]. It consists in visual determination of the fabric oil resistance during application of mineral (paraffinic) oil and n-Heptane (C7H16) to it in different ratios. As a result, it was identified that the fabrics "Bordo - Indura", "Antistat", "Premier-Comfort 250A", "Indura-235", "Indura-325" exhibit high oil resistance (100/110 units). The fabrics "Greta-M" and "Premier-Standart 210" exhibit satisfactory oil resistance (80/90 c.u.), and "Master-Lux CA27" - low oil resistance (50/60 c.u.).

The sales were treated with the extract containing $2 \mathrm{ml}$ of chloroform. The obtained chloroform extracts is in Fig.1.

For extension of special-purpose clothes lifetime and retention of protective and hygienic properties, PPE chemical cleaning is used [15]. Chemical (dry) cleaning, as the method for special-purpose clothes treatment, has great advantages before washing [16].

To determine qualitative and quantitative composition of the oil refinery workers' special-purpose clothes contamination, the samples of protective clothing external tissues $(50 \times 50 \mathrm{~mm})$ obtained from different areas of contaminated overall were researched. Research of textile material properties and structure with account of operation mode allows obtaining the data for clothes protection stability forecasting $[17,18]$. Chloroform extracts (Fig.1) were subject to investigation using the method of the capillary gas chromatography [19] with mass selective detection. 


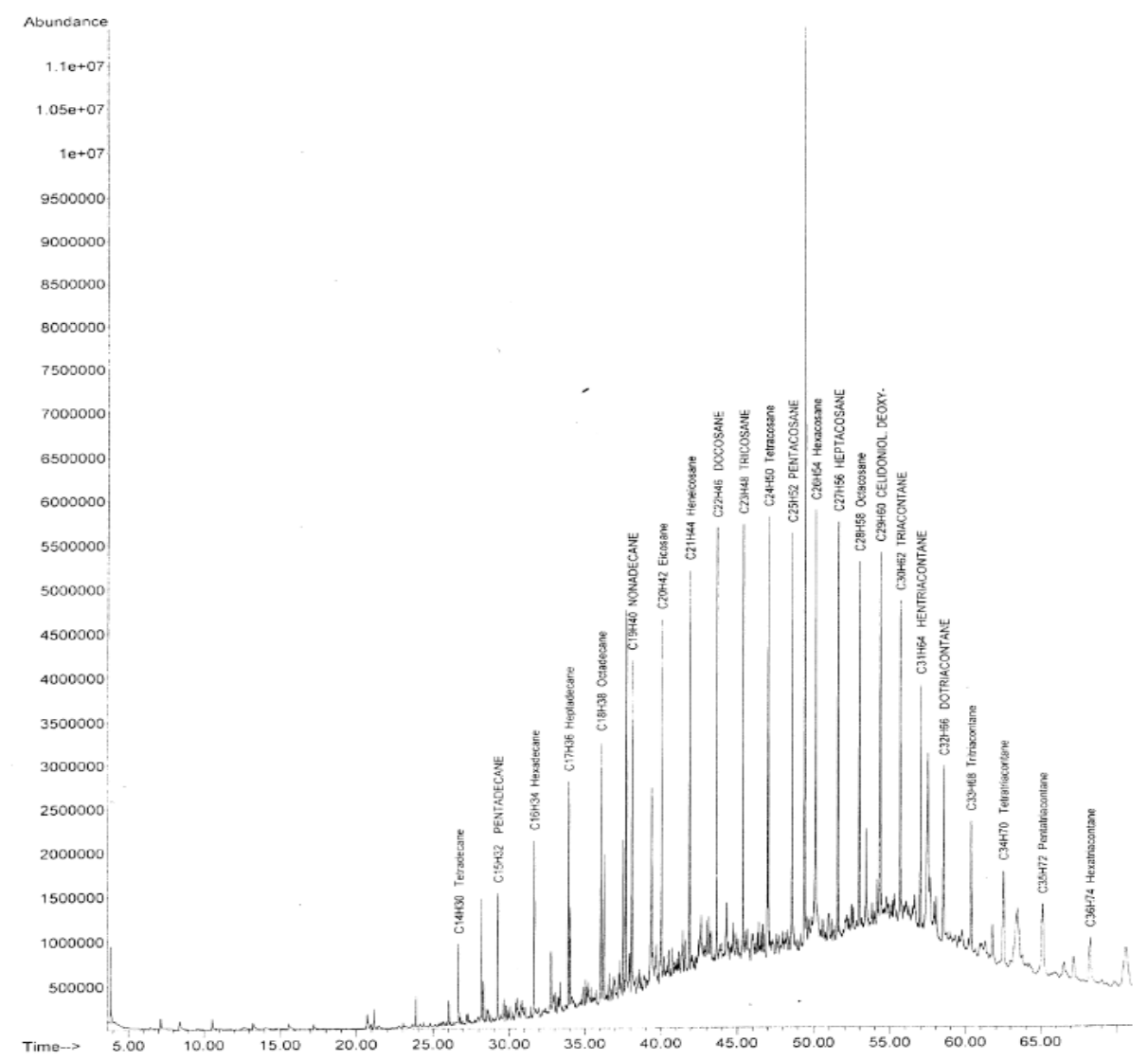

Fig. 1. The mixed fabric chromatogram for special-purpose clothes after production contaminations at oil refinery (seat part of trousers, seat surface).

Agilent Technologies 7820A chromatograph, Agilent Technologies 5975 detection unit.

Recording and processing of chromatograms was performed in the chemical station Enhanced ChemStation G17001 DA Version D.01.02 Agilent Technologies.

Chromatograms for contamination areas of the knee level rear parts of trousers, of the jacket lower parts and of the sleeves on the elbow level were obtained. For analysis of contaminants removal efficiency, the hydrocarbons were clustered into blocks based on their physical properties. For calculation of content in the cleaned samples, concentration of oil products in the initially contaminated samples was taken for $100 \%$. After that, the materials under testing were exposed to chemical cleaning technology [20] and were examined again using the method of chromatography.

\section{Discussion of the findings. Practical relevance}

Based on the obtained chromatograms it was identified that the main component of contaminants - hydrocarbons from $\mathrm{C} 14 \mathrm{H} 30$ Tetradecane to $\mathrm{C} 36 \mathrm{H} 74$ Hexatriacontane are present in clothes with high concentration level. For the block of hydrocarbons C14H30$\mathrm{C} 16 \mathrm{H} 34$, the average concentration values of hydrocarbons on the cleaned samples for all clothes surface areas made from 1.8 to $10.6 \%$, for block $\mathrm{C} 17 \mathrm{H} 36-\mathrm{C} 25 \mathrm{H} 52$ from 3.28 to $14.7 \%$, for block C26H54 - C32H66 from 0.96 to 7.55 and for block C33H68 - C36H74 
from 0.45 to 2.25 percent. The determined data reduced to distribution system of contaminating surfaces allowed establishing that accumulation of residual contaminations, which were not removed from the material structure by means of chemical cleaning, are formed by the block of saturated hydrocarbons $(\mathrm{C} 17 \mathrm{H} 36-\mathrm{C} 25 \mathrm{H} 52)$ with their maximum manifestation in the surface areas of elbow-sleeves. Taking into account that the elbowsleeve area is very critical in formation of electrostatic risks on the human surface, the determined data of presented research allow justifying implementation of the sleeve material correction using the anti-electrostatic film coatings.

\section{References}

1. TR CU 019, 878 (2011)

2. The energy strategy of Russia for the period up to 2030, 1715-r (2009)

3. E.V. Yakovleva, I.K. Mihalko, The prob. of secur. in the mode.worl., 81 (2017)

4. K. Singha Amer. Jour. of Polym. Scien., 2(3), 39 (2012)

5. Report from a government assignment, Swed.Chemic.Agen. Arkitektkopia, 142 (2014)

6. U.S. EPA, Semarn.Pollut. Preven. Work, 12, 167(167) infohouse.p2ric.org/ref/20/19041.pdf.

7. W.B. Achwal Chemic. Processing. Colourage, 9, 40 (1990)

8. Guide produced by the environmental technology best practice programme, 62 (1997) http:// www.wrap.org.uk/sites/files/wrap/GG062.pdf

9. S.Saxena, A.Raja, A.Arputharaj, Textil.Scien.and Cloth.Technol, 44 (2017)

10. A.Arputharaj, AlRaja, S.Saxena, Gr.fash, 217 (2015)

11. I.Cherunova A.Korinteli, T.Lesnikova, Sol.St. Phenom, 265, 187 (2017)

12. M.A.Safronova, Over. and spec.foot wear for work. in the chem, 2 (1984)

13. I.V.Cherunova, S.A.Kolesnik, S.V.Kurenova, Yu.V.Eremina, A.V.Merkulova, P.V.Cherunov, Int.Journ.of Appl.Eng.Res., 10(19), 40506 (2015)

14. E.V.Yakovleva, O.N.Baranik, E.E. Rudenko, Text. Cloth.,Footw. Pers. Prot.Equip. in the 21 st cent., 99 (2012)

15. E.V.Yakovleva, S.V.Kostromina, Trend.in the Form. of Mod. Scien., 4, 264 (2014)

16. M.A.Safronova, Over.and spec.footw.for Work. in the Chem., Ref. and Petrochem. Industr., 2 (1984)

17. I.V.Cherunova, M.P.Stenkima, P.V.Cherunov, Proceed.of Struct. Membran., 210 (2017)

18. P.Cherunov, S.Knyazeva, M.Stenkina, E.Stefanova, N.Kornev, Proceed.of Struct.Membran., 555 (2015)

19. M.J.Dennis, R.C.Massey, D.J.McWeenyBonny, L.A.Anders-Eriksson, G.Sahlberg, Journ.of Chromat., 285, 127 (1984)

20. GOST R 51108-2016.Standartinform (2017) 